
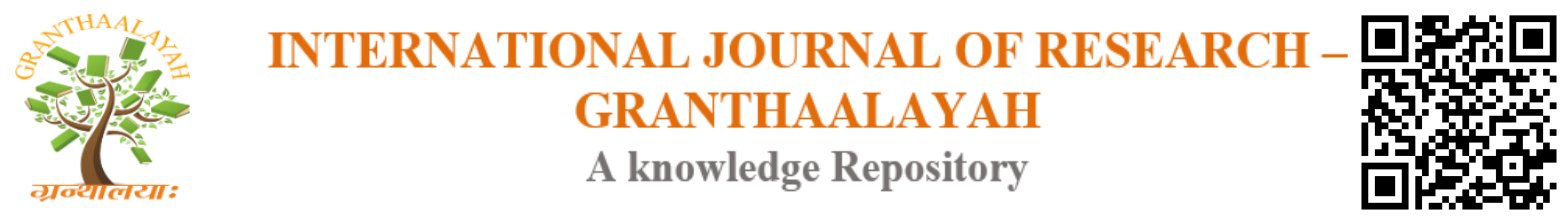

Science

\title{
PASSIVE DOSIMETRY: COMPARATIVE STUDY BETWEEN TWO EVALUATION METHODS OF OCCUPATIONAL EXPOSURE TO PESTICIDES
}

\author{
Francisco Alves Pinheiro *1, José Lourenço do Egito ${ }^{2}$, Paulo José Adissi ${ }^{3}$ \\ ${ }^{*}$ Department of Production Engineering, Federal University of São Francisco Valley, Brazil \\ ${ }^{2,3}$ Department, of Production Engineering, Federal University of Paraiba, Brazil
}

\begin{abstract}
The present study aims to compare the passive dosimetry sampling and census methods for the evaluation of pesticide exposure. The studies were carried out in the city of Petrolina - PE, in the São Francisco River Valley, under three working conditions: weeds, grape and acerola cultivation with the use of a hand-held sprayer in the Brazilian summer. For data analysis, descriptive statistical parameters and Student's T-test were used to compare the means of paired samples. Both methods evaluated the simulated manual application of pesticides. Given the results, it was concluded that there was a high discrepancy between exposure assessments in all treatments, with the sample method showing overestimated values, with differences greater than $200 \%$ and that the census method showed more reliable and accurate results with greater efficiency.
\end{abstract}

Keywords: Passive Dosimetry; Occupational Exposure; Sampling Exposure Method; Full Body Exposure Method; Pesticides.

Cite This Article: Francisco Alves Pinheiro, José Lourenço do Egito, and Paulo José Adissi. (2019). "PASSIVE DOSIMETRY: COMPARATIVE STUDY BETWEEN TWO EVALUATION METHODS OF OCCUPATIONAL EXPOSURE TO PESTICIDES.” International Journal of Research - Granthaalayah, 7(9), 52-62. https://doi.org/10.29121/granthaalayah.v7.i9.2019.559.

\section{Introduction}

The risk of human poisoning from potential exposure to pesticides has been studied by the scientific community as a serious public health problem, as it directly affects workers and consumers, and society at large through environmental contamination, especially in developing countries [1-4]. The International Labor Organization and the World Health Organization [5] estimate that in developing countries annually, 7 million workers are poisoned by pesticides and that 70,000 of them die.

Studies on this theme adopt both qualitative approaches, focusing from public prevention and control policies to the subjectivity of exposed workers, and quantitative, to estimate the doses that 
workers would potentially absorb in the various work situations with pesticides. These estimates are called passive dosimetry.

For passive dosimetry it is necessary to collect samples of the substances that would be absorbed by the workers during a work day and, for that, special absorbent clothes or samplers can be used in real (with pesticides) or simulated (with dyes or other indicators) work situations.

In this study a comparison was made between the sampling method when using samplers, and the census method when using a full body exposure suit to assess dermal exposure to pesticides in simulated work situations with the use of dyes, considering only the activity of manual application of pesticides with manual costal sprayer.

\section{Evaluation of Pesticides Exposure by Passive Dosimetry}

According to the OECD [6], the pioneers of passive dosimetry exposure assessment for pesticides were Durham and Wolfe [7], who first employed the sampler method.

In 1975, the World Health Organization (WHO) developed the first protocol (WHO Protocol) for the evaluation of exposure to organophosphate products, using absorbent samplers to measure dermal exposure. As early as 1982, the protocol was revised and extended for all pesticides. This review included quantification of dermal exposure by the whole-body method [6].

For Kotaca [8] the most significant methodological contributions that continued to seek the standardization of passive dosimetry for evaluation of dermal exposure by pesticides were as follows:

- Fenske [9] who developed the method using fluorescent dyes,

- Lundehn and Westphal [10] presented guidelines for the use of the sampling method;

- The United States Environmental Protection Agency [11] published the "Guidelines for Exposure Assessment", which outlines the key aspects and objectives of exposure assessment and published still in 1996 the "Occupational and Residential Exposure Test Guidelines", that oriented the use of passive dosimetry and biological monitoring.

- Chester [12] sought to standardize the different evaluation methods in his publication "Harmonized Guidance for the Conduct of Operator Exposure Studies".

- The Organization for Economic Cooperation and Development [6], based on Chester's contribution, published the "Guidance Document for the Conduct of Studies on Occupational Exposure to Pesticides During Agricultural".

\subsection{The Sampling Method}

To assess the level of contamination by the sampling method, should be used a variable number of samplers (cotton, gauze or appropriate paper) that was fixed on the workers' garments at previously defined points, as indicated in the standard protocol of the [13].

The exposed surface area of each sampler is standardized to approximately $10 \mathrm{x} 10 \mathrm{~cm}\left(100 \mathrm{~cm}^{2}\right)$. The result of treatment analysis will be measured in $\mu \mathrm{g} / \mathrm{cm}^{2}$ or $\mathrm{mg} / \mathrm{cm}^{2}[6]$. 
Figure 1 shows the body region of the worker, areas of body segments and the location where the absorbent sampler should be fixed.

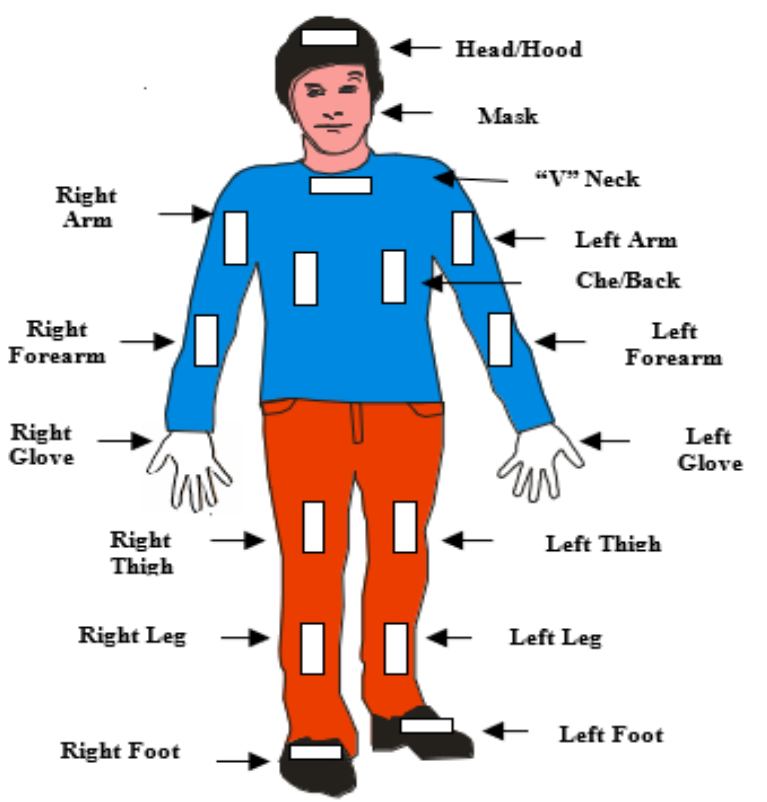

\begin{tabular}{cc}
\hline Parts of Bady & Body Area $\left(\mathrm{cm}^{2}\right)$ \\
\hline Head/Hood & 1300 \\
Neck (back) & 110 \\
Neck (front) & 150 \\
Back & 3550 \\
Chest & 3550 \\
Arm & 2910 \\
Forearm & 1210 \\
Thigh & 3820 \\
Leg & 2380 \\
Foot & 1310 \\
Hand & 820 \\
\hline
\end{tabular}

Figure 1: Sampling points in the worker's body (EPA/USEPA [11])

To estimate the potential dermal exposure of each body region, a homogeneous dose within the area is considered and the standardized anthropometric dimensions shown in Figure 1. Thus, the doses captured by the samplers are extrapolated to the entire body region from the factors of the body. expansion calculated by the ratio of the standard body surface area to the sampler area (s).

The adoption of expansion factors, as they are not based on actual anthropometric surveys and consider homogeneous doses within the body segments, may cause errors in estimation of exposure.

In the specialized literature there are several applications of the sampling method. In Brazil, we highlight the research by Machado Neto [14-15] and Ramos et al [16] that evaluated the application conditions of pesticides in crops such as grapes, eucalyptus, soybeans and peanuts. The contributions of Hines et al. [17] in the evaluation of pesticide exposure in American apple and peach plantations and by Farahat et al. [18] in cotton growing areas in Egypt.

\subsection{Full Body Method}

The evaluation of dermal exposure through the "full body method" is made with the use of light jumpsuits or similar clothing that work as dosimeters $[13,19,6,20]$ can also be applied not only in simulated work with dyed water pulverization on defined targets, but also in real treatment situations with pesticides.

The head exposure is measured with the use of an associated (cap) to the jumpsuit, the hand and feet exposure, by their hand, are measured with the use of gloves and socks, to the rest of the body parts clothing sections from the test are utilized [21]. 
After the exposure period, the jumpsuit must be removed and sectioned (figure 2) and each part is storage separately to laboratorial analysis.

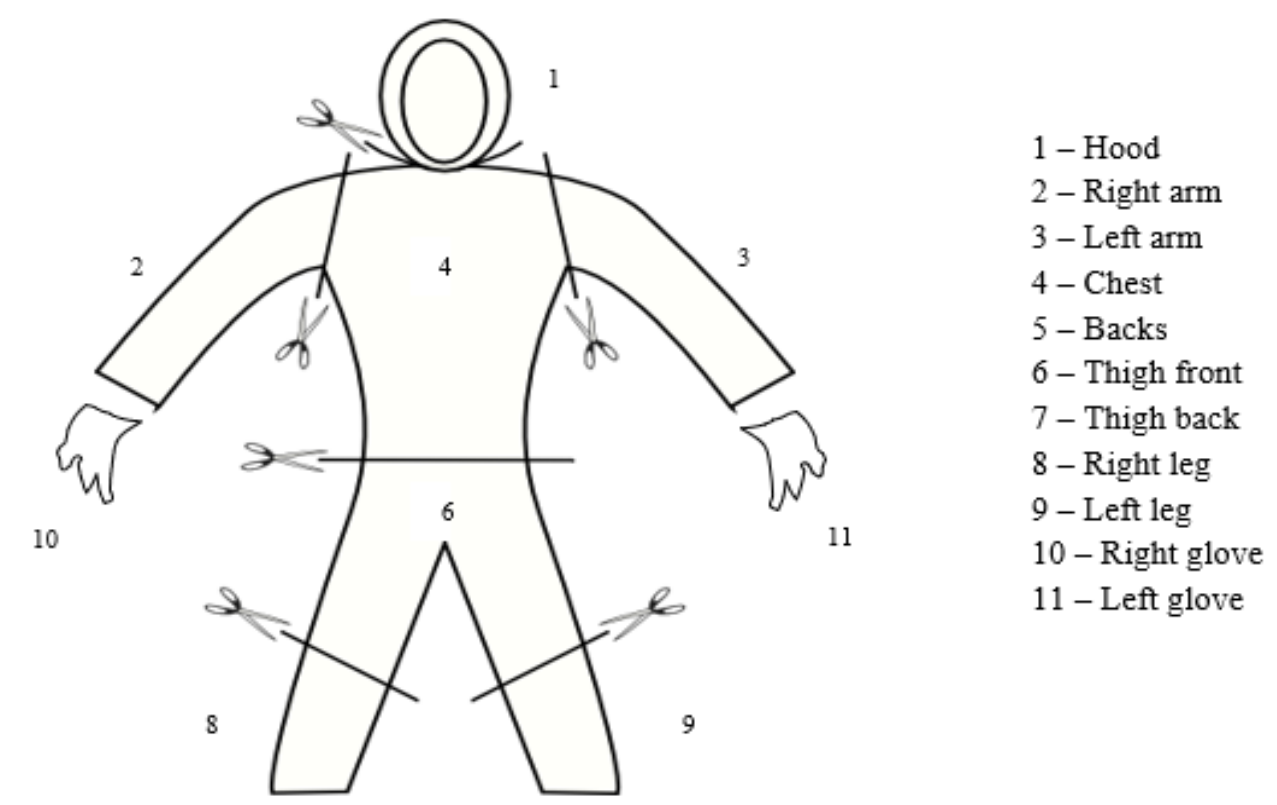

Figure 2: Division outfit full body parts (adapted by Adissi e Pinheiro [22])

The adoption of this method has been occurring more among European researchers such as Frenich et al. [23] who evaluated dermal exposure in workers who apply pesticides in vegetable greenhouses in the region of Almeria / ES, Tsakirakis et al. [24] who studied the case of olive growers in Greece, Hughes et al. [25] who carried out an evaluation of the conditions of use of hand sprayers in small agricultural production units in Argentina. In Brazil, studies by Pinheiro [26] and Adissi and Pinheiro [22] in fruit growing situations stand out.

\subsection{Comparison Between Methods}

The main operating differences of the methods studied are the costs involved, setup times and operator comfort. These conditions are all favorable to the sampling method that demands lower material costs, shorter preparation times and, by changing less the normal operating conditions, allows a superior comfort to the workers involved. This last aspect, because it directly interferes with the work performed, is the most important advantage of the sampling method. On the other hand, the census method is considered more accurate because it does not require extrapolations. The difference in accuracy between the methods is the central focus of this article.

\section{Materials and Methods}

Aiming to verify the accuracy of the passive dosimetry sampling method for the evaluation of exposure by pesticides in manual application with costal sprayer, field tests were performed in the São Francisco River Valley, Brazil.

The treatments were carried out by four workers under simulated weed, fungus and insect control conditions in the horizontally supported grape crop and by two workers under simulated fungal 
and insect applications in the acerola crop. These treatments were selected to cover three types of targets located below (weed application), above (application above head), and at front (operator's chest height) as shown (Figure 3).

In order to avoid differences between application conditions arising from the relationship of operator position and wind direction and intensity, the tests observed were unique. That is, the same test was analyzed by both methods. For this, the operators were dressed in the overalls of the census method and the samplers were fixed on them. With this decision, the only condition that can be analyzed was the accuracy of the methods.

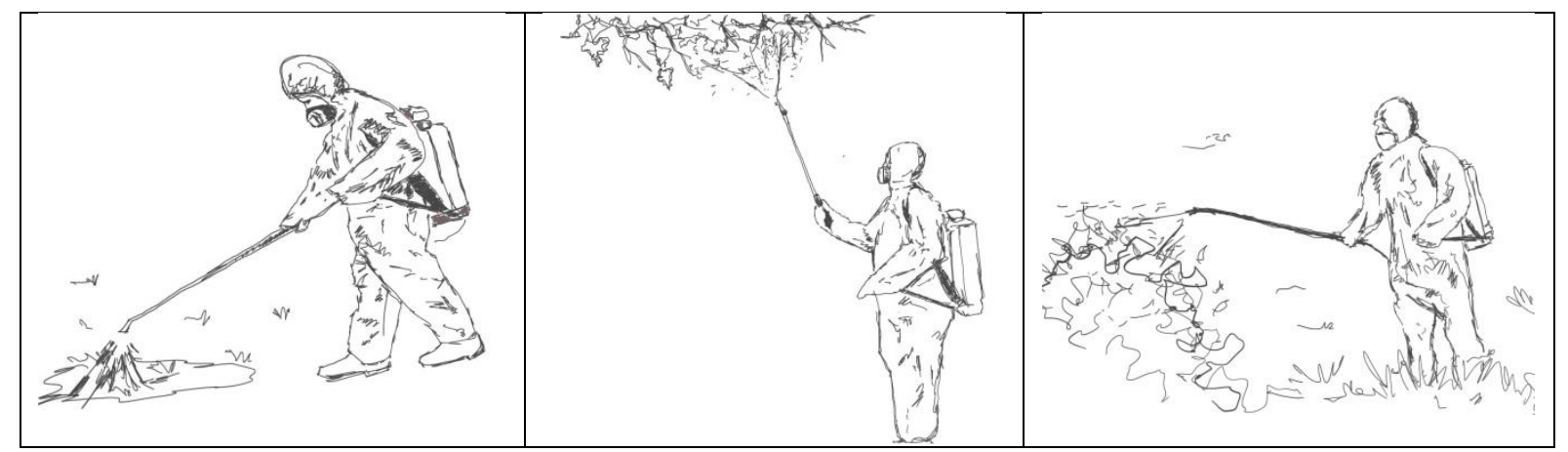

Figure 3: Field tests: down, up and forward application simulations

The manual costal sprayer used was of the brand STRONG with capacity of $20 \mathrm{~L}$, with conical nozzle and JA2 tip. The operator's outfit was a nonwoven ${ }^{1}$ absorbent jumpsuit and rubber boots. The Intimus ${ }^{\circledR}$ brand female absorbent was used as a sampler and the applied grouts were composed of the FD Bright Blue food colorant diluted in the proportion of $500 \mathrm{ml}$ for each 10 liters of water.

To perform the experimental field trials, 6 male volunteer workers with experience in the handling and application of pesticides were selected. After explaining the research objectives and signing the free and informed consent form to participate in the field experiments, the applicators were instructed by the researcher to perform their task as if they were applying pesticide to the desired target.

In the downward weed control test, the applicators ran five rows (alternating) with 64 plants, spacing $3.5 \mathrm{~m}$ by $3.0 \mathrm{~m}$ corresponding to an area of $672 \mathrm{~m}^{2}$. Each applicator used two tanks per simulation. Then new applications were made, which were performed on the top of the vine (grape) in another area $\left(638 \mathrm{~m}^{2}\right)$ of the same orchard, with both applicators wearing new garments. The time used by each applicator during each test was of 30 minutes, including the tank refueling time. During the evaluation periods in both treatments, the air remained at $32.7^{\circ} \mathrm{C}, 51.3 \%$ relative humidity and $2 \mathrm{~m} / \mathrm{s}$ average speed.

The following day, the experimental tests were performed under the same working conditions and in the same place, using the same procedures as the previous day, but with two new workers and clothing. The worker application time during weed spraying was of 30 minutes. At the time of

\footnotetext{
${ }^{1}$ According to NBR-13370, nonwoven is a flat, flexible and porous structure consisting of a veil or blanket of directional or randomly oriented fibers or filaments, consolidated by mechanical (friction) and / or chemical (adhesion) process and / or thermal (cohesion) and combinations thereof.
} 
application, the air temperature was $28.4^{\circ} \mathrm{C}$ with a relative humidity of $54.5 \%$ and an average velocity of $2.3 \mathrm{~m} / \mathrm{s}$.

The tests for dermal exposure (DE) assessment of acerola crop workers (applicator chest level) were attended by two volunteer applicators. During the simulation, each worker used two tanks to apply the product, covering an area of $457 \mathrm{~m}^{2}$. The duration of the trials was 30 minutes, including stopping to replenish the sprayer tank. The atmospheric conditions at the time of the tests were as follows: temperature of $32.4^{\circ} \mathrm{C}$, relative humidity $47.7 \%$ with average velocity of $3.1 \mathrm{~m} / \mathrm{s}$.

After sectioning the parts of the overalls sampled, the extractions of the parts and samplers with $10 \%$ diluted acetone were performed.

To obtain the dye concentration and spectrophotometer readings, two calibration curves were constructed for the analysis of the samples, one for the grape culture experiments (down and up applications) and the other for the acerola culture experiments, with 6 concentration levels $(0.25$, $0.5,0.75,1.0,1.25$ and 1.5$)$, yielding concentration regression curves as a function of absorbance: $\mathrm{y}=0,5361 \times 0.0125$ with $\mathrm{R}^{2}=0.992$ and $\mathrm{y}=0.134 \times 0.002$ with $\mathrm{R}^{2}=0.998$.

The extracted solution from each sample was filtered and then stirred for 30 minutes and placed in cuvettes for spectrophotometer readings. Readings were taken in the same way for both sets of samples (female pads and overalls sections).

From the absorbance reading the concentrations $\left(\mathrm{C}_{i}\right.$ in $\left.\mu \mathrm{g} / \mathrm{ml}\right)$ were calculated through the curves previously defined, allowing the determination of the amounts of grout that reached the body $\left(\mathrm{Q}_{i}\right.$ in $\mu \mathrm{g}$ ), since the volumes used in the measurement are known. extraction $\left(\mathrm{V}_{i}\right)$. Finally, it is estimated the dermal exposure $\left(\mathrm{ED}_{i}\right.$ in $\mathrm{ml} /$ day) resulting from the activity, through the application tank syrup concentration $\left(\mathrm{C}_{T}\right)$ and the application time, through the expressions:

$C_{i}=\frac{A_{i}-b}{a}, Q_{i}=C_{i} . V_{i}$ e $E D_{i}=\frac{Q_{i} \cdot t_{j}}{C_{T} \cdot t_{e}}$

Where: $t_{\mathrm{e}}$ is the duration of the experiment and $t_{\mathrm{j}}$ the duration of exposure throughout the journey. To quantify exposure by the sampling method, it is necessary to apply an expansion factor to extrapolate the results from the sampler to the body segment, through the expression:

$$
F E_{i}=\frac{A_{i}}{A_{a m}}
$$

Where: $\mathrm{FE}_{\mathrm{i}}-$ expansion factor for body segment $\mathrm{i}$;

$\mathrm{A}_{\mathrm{am}}$ - sampler area $\left(85.25 \mathrm{~cm}^{2}\right)$;

$A_{i}$ - body surface area $i$.

For the census method, to obtain dermal exposure of the body segment, the concentration of the sampler was added to that of the cut. 
Statistical analysis was performed to verify the presence of significant differences between the two study methods, based on the Student's T test for paired data, using the Microsoft Excel 2016 spreadsheet.

\section{Results and Discussions}

Table 1 presents the results of dermal exposures estimated by both study methods. Student's T test (95\% significance) showed significant differences between the method estimates for both downward $(\mathrm{p}=0.009)$ and upward $(\mathrm{p}=0.0000036)$ and forward applications, that is, the chest level of the applicator $(\mathrm{p}=0.0115)$.

In the weed treatment (downward application) two application patterns were verified, as applicators 1 and 2 received loads equivalent to $75 \%$ of the total load. Among the body segments, consistent with the nature of the activity, the lower limbs were the hardest hit, receiving $64 \%$ of the loads. In all cases, the sampling method indicated overestimations that, on average, showed differences of $359 \%$, reaching a difference of $1500 \%$ between the estimates of back exposure.

In the treatment of the aerial parts of the grape crop (upward application) two application patterns were also observed as the applicators 1 and 2 concentrated $71 \%$ of the loads. Now here, since the boom was directed upwards, the upper limbs were the hardest hit (52\% of loads). Between the methods there were significant differences in the order of $233 \%$ of overestimation of the sampling method, reaching a difference of over $700 \%$ for the evaluation of the loads that reached the workers back (Table 1).

In the case of the forward treatment in acerola crop, where only two workers participated in the experiment, there was a greater balance between applications (A2 with 59\% of loads). In this case, the most affected body segments were the lower limbs (57\%), followed by the upper limbs, which together concentrated $86 \%$ of the loads.

Overestimation of the sampling method averaged $350 \%$ above the census method, reaching a point estimate of more than $1500 \%$ (chest).

Table 1: Estimates of dermal exposures, sampling method and census method

\begin{tabular}{|c|c|c|c|c|c|c|c|c|c|c|c|}
\hline \multirow[t]{2}{*}{ Application methods } & \multirow{2}{*}{$\begin{array}{l}\text { Body } \\
\text { Parts }\end{array}$} & \multicolumn{5}{|c|}{ Sampling method (ml/journey) } & \multicolumn{5}{|c|}{ Census method (ml/journey) } \\
\hline & & A1 & A2 & A3 & A4 & Average & A1 & A2 & A3 & A4 & Average \\
\hline \multirow[t]{6}{*}{ Downward } & Head & 0.00 & 0.00 & 0.00 & 0.00 & 0.00 & 0.00 & 0.00 & 0.00 & 0.02 & 0.01 \\
\hline & Chest & 0.00 & 0.00 & 0.00 & 0.00 & 0.00 & 0.13 & 0.00 & 0.03 & 0.07 & 0.06 \\
\hline & Back & 6.40 & 7.25 & 0.00 & 0.00 & 3.41 & 0.44 & 0.35 & 0.02 & 0.03 & 0.21 \\
\hline & $\begin{array}{l}\text { Upper } \\
\text { members }\end{array}$ & 2.28 & 1.79 & 0.00 & 0.00 & 1.02 & 1.07 & 0.39 & 0.50 & 0.07 & 0.51 \\
\hline & $\begin{array}{l}\text { Lower } \\
\text { members }\end{array}$ & 2.46 & 9.52 & 3.67 & 6.68 & 5.58 & 2.24 & 1.95 & 0.67 & 0.73 & 1.40 \\
\hline & Total & 11.15 & 18.56 & 3.67 & 6.68 & 10.02 & 3.88 & 2.69 & 1.23 & 0.93 & 2.18 \\
\hline \multirow[t]{3}{*}{ Upward } & Head & 4.90 & 2.60 & 1.66 & 4.65 & 3.45 & 1.67 & 0.54 & 0.38 & 0.72 & 0.83 \\
\hline & Chest & 10.37 & 6.74 & 3.53 & 5.15 & 6.45 & 2.24 & 0.82 & 0.27 & 0.36 & 0.93 \\
\hline & Back & 3.04 & 2.90 & 0.74 & 7.38 & 3.52 & 0.56 & 0.44 & 0.22 & 0.42 & 0.41 \\
\hline
\end{tabular}


DOI: 10.5281/zenodo.3464380

\begin{tabular}{|c|c|c|c|c|c|c|c|c|c|c|c|}
\hline & $\begin{array}{l}\text { Upper } \\
\text { members }\end{array}$ & 10.93 & 2.10 & 3.47 & 6.45 & 5.74 & 7.12 & 4.49 & 2.55 & 2.35 & 4.13 \\
\hline & $\begin{array}{l}\text { Lower } \\
\text { members }\end{array}$ & 12.87 & 5.20 & 5.14 & 6.50 & 7.43 & 3.33 & 1.48 & 1.05 & 0.91 & 1.69 \\
\hline & Total & 42.13 & 19.55 & 14.55 & 30.14 & 26.59 & 14.94 & 7.77 & 4.46 & 4.76 & 7.98 \\
\hline \multirow[t]{6}{*}{ Foward } & Head & 0.59 & 1.43 & - & - & 1.01 & 0.08 & 0.21 & - & - & 0.15 \\
\hline & Chest & 3.02 & 2.68 & - & - & 2.85 & 0.18 & 0.17 & - & - & 0.17 \\
\hline & Back & 0.00 & 0.89 & - & - & 0.45 & 0.12 & 0.05 & - & - & 0.09 \\
\hline & $\begin{array}{l}\text { Upper } \\
\text { members }\end{array}$ & 1.40 & 2.68 & - & - & 2.04 & 0.73 & 0.89 & - & - & 0.81 \\
\hline & $\begin{array}{l}\text { Lower } \\
\text { members }\end{array}$ & 6.81 & 11.47 & - & - & 9.14 & 1.22 & 2.00 & - & - & 1.61 \\
\hline & Total & 11.82 & 19.16 & - & - & 15.49 & 2.31 & 3.32 & - & - & 2.82 \\
\hline
\end{tabular}

Source: elaborated by the authors based in the research

In general. the results of simulated dermal exposure verified between the three treatments by the sampling and census method showed significant differences in values between exposure evaluations. Figure 4 presents the synthesis of the comparison between the results of the methods.

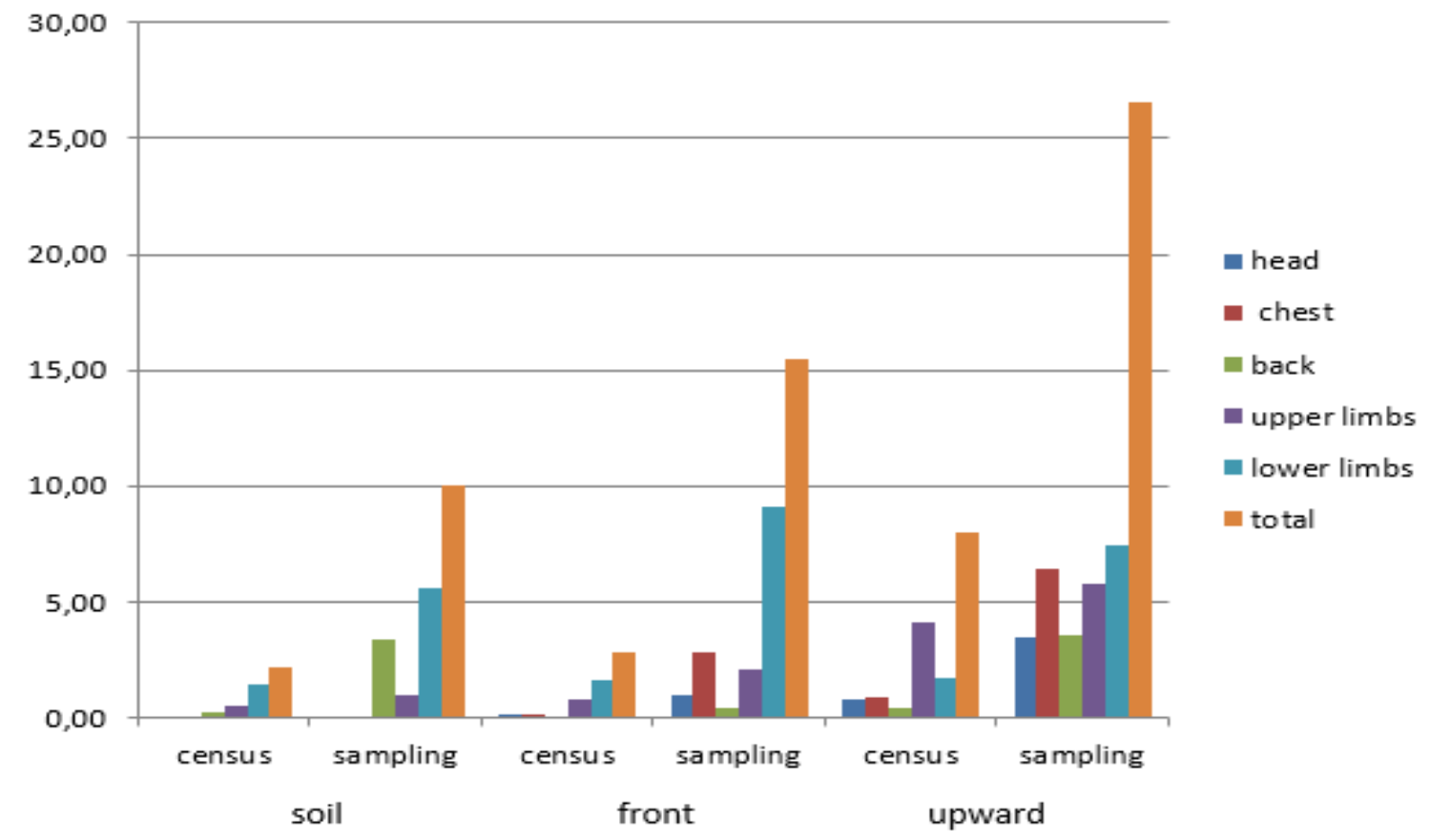

Figure 4: Comparison of average exposures, by body part (ml/journey)

It is observed that upward application (61\%) is the one that most exposes workers. followed by forward application at the chest level (22\%). And it is precisely in these types of applications that the greatest overestimations of the sampling method occurred. Among the body segments. the overestimation profile was different. since although the limbs received the highest loads (42 and 36\% upper and lower) the largest differences between the methods occurred at the chest level ( $900 \%$ in the back and $700 \%$ in front of the chest). 


\section{Conclusions and Recommendations}

In terms of accuracy it is clear that the census method is the best of methods since the results obtained by the sample method presented high discrepancies and potential errors in their estimates. These differences may be explained by the need to include an expansion factor of the samplers to extrapolate their values to the entire section area that is represented. This procedure can introduce two types of errors: the factor being dissonant from reality and the sample not being representative of the actual exposure.

The first question derives from the use of factors based on anthropometric patterns rather than actual anthropometric measurements. While the second refers to the differences between the exposure concentration of the samplers for the complete segments. since this concentration is not homogeneous in the body segment and the absorbent samplers tend to be fixed in the places where the highest concentrations occur.

To reduce these variations the use of standard anthropometric values can be avoided by substituting them with actual data from the applicators. And regarding the representativeness of the sample. the adoption of two samplers per body segment is recommended.

These differences do not invalidate the use of the sampling method. which offers more favorable operating conditions. but should be considered in their applications and cannot be used for absolute conclusions. being more suitable for comparative analysis. On the other hand. it is important to note that the tendency to overestimate exposure leads to safer decisions in terms of occupational contamination risk analysis.

\section{References}

[1] Rebelo, F. M. et al. (2011). Intoxicação por Agrotóxicos no Distrito Federal. Brasil. de 2004 a 2007 - Análise da Notificação ao Centro de Informação e Assistência Toxicológica. Ciência \& Saúde Coletiva. vol.16, No. 8, 2011, Rio de Janeiro/RJ.

[2] Ntow, W. J. et al. Occupational Exposure to Pesticides: Blood Cholinesterase Activity in a Farming Community in Ghana. Arch Environ Contam. Toxicol. Vol. 56, 2009, 623-630

[3] Lu, J. L. Total Pesticide Exposure Calculation Among Vegetable Farmers in Benguet. Philippines. Journal of Environmental and Public Health. vol. 2009, 2004, 5 pages.

[4] Kumar, A. et al. (2011). Assessment of Acute Toxicity of $\lambda$-cyhalothrin to a Freshwater Catfish. Clarias batrachus. Environ. Chen. Lett. Vol. 9, 2011, 43-46.

[5] ILO/WHO. Joint Press Release ILO/WHO: Number of Work-related Accidents and Illnesses Continues to Increase - ILO and WHO join in call for prevention strategies, 2005. Disponível em <http://www. ilo.org/public/english/bureau/inf/pr/2005/21.htm.>. Acesso em 14/11/2018.

[6] OECD - Organization for Economic Co-Operation and Development. Guidance Document for the Conduct of Studies of Occupational Exposure to Pesticides During Agricultural Application. Series on testing and assessment. 9. Paris, 1997, 57p.

[7] Durham, W. F. \& Wolfe, H. R. Measurement of the Exposure of Workers to Pesticides. Bull World Health Organ. Vol. 26, No. 1, 1962, 75-91.

[8] Kotaka, E. T. Avaliação da Exposição de Trabalhadores a Agrotóxicos: Contribuições para a realização da Dosimetria Passiva pelo Método do Corpo Total e Monitoramento Biológico. Tese (doutorado) Universidade Estadual de Campinas - Unicamp. Campinas/SP, 2005. 
[9] Fenske, R. A. \& Day Junior, E. Assessment of Exposure for Pesticide Handlers in Agricultural. Residential and Institutional Environments. Occupational and Residential Exposure Assessment for Pesticides. Seattle. WA. USA, 2005.

[10] Lundehn, J. R.; Westphal, D.; Kieczka, H.; Lo“chler-Bolz, S.; Maasfeld, W.; Pick, E. D. Uniform Principles for Safeguarding the Health of Applicators of Plant Protection Products (Uniform principles for operator protection). Mitteilungen ausder Biologischen Bundesanstalt für Land- und Forstwirts-chaft Berlin-Dahlem. Heft 277. Berlin, 1992.

[11] EPA/USEPA - Environmental Protection Agency. Guidelines for Exposure Assessment. Washington. Federal Register Vol. 57, No. 104, 1992, 22.888-22.938.

[12] Chester, G. Harmonized Guidance for the Conduct of Operator Exposition Studies. In: Environmental and human health risk assessments for agrochemicals conference. Londres, 1996.

[13] WHO - World Health Organization. Field Surveys of Exposure to Pesticides - Stand Protocol. Pesticide development safe use unit division of Vector Biology and Control. Geneva: WHO, 1982.

[14] Machado Neto, J. G. Estimativas do Tempo de Trabalho Seguro e da Necessidade de Controle da Exposição Ocupacional dos Aplicadores de Agrotóxicos. Jaboticabal. FCAV/Unesp. (tese de Livre Docência em Ecotoxicologia dos Agrotóxicos e Saúde Ocupacional). Jaboticabal, 1997.

[15] Machado Neto, J. G. Segurança no Trabalho com Agrotóxicos em Cultura de Eucalipto - FUNEP. SP - Campus de Jaboticabal, 2001.

[16] Ramos, H. H. et al. (2002). Exposição dérmica do aplicador de agrotóxicos na cultura da uva. com diferentes pulverizadores. Revista Brasileira de Engenharia Agrícola Ambiental. Vol. 6, No. 1, 2002, Campina Grande - PB.

[17] Hines, C. J. et al. (2008). Captam Exposure and Evaluation of a Pesticide Applicators in Agricultural Health Study. Ann. Occup. Hyg. Vol. 52, No. 3, 2008,153-166.

[18] Farahat, F. M. et al. Chlorpyrifos Exposure in Egyptian Cotton Field Workers. Neurotoxicology. Vol. 31, No. 3, 2010, 297-304.

[19] Abbott, I. M.; Bonsall, J. L.; Chester, G.; Hart, T. B. and Turnbull, G. J. (1987). Worker exposure to a herbicide applied with ground sprayers in the United Kingdom. Vol. 48, 1987, 167-175.

[20] Glass, C. R. Exposure of Agricultural Workers to Pesticides in Southern Europe. In: Seminário Internacional sobre uso de Agrotóxicos. João Pessoa. Anais... João Pessoa, 2000; UFPB.1 Cd-Rom.

[21] Soutar, A. et al. Use of Patches and Whole-Body Sampling for the Assessment of Dermal Exposure. The Annals of Occupational Hygiene. Vol. 44, 2000, 511-518.

[22] Adissi, P. J. and Pinheiro, F. A. Análise de Risco na Aplicação Manual de Agrotóxicos: o Caso da Fruticultura do Litoral Sul Paraibano. In: XXV - ENEGEP. Porto Alegre. RS. Anais... Porto Alegre, 2005.

[23] Frenich, A. G. et al. Dermal Exposure to Pesticides in Greenhouses Workers: Discrimination and Selection of Variables for Design of Monitoring Programs. Environmental Monitoring and Assessment. 80, 2002, 51-63.

[24] Tsakirakis, A.; Kasiotis, K. M.; Arapaki, N.; Charistou, A.; Tsatsakis, A.; Glass, C. R.; Machera, K. Determination of Operator Exposure Levels to Insecticide During Bait Applications in Olive Trees: Study of Coverall Performance and Duration of Application. International Journal of Hygiene and Environmental Health. Vol. 214, No. 1, 2011, 71-78.

[25] Hughes, E. A. et al. Potential Dermal Exposure to Deltamethrin and Risk Assessment for Manual Sprayers: Influence of Crop Type. Science of the Total Environment. Vol.391, No. 1, 2008, 34-40.

[26] Pinheiro. F. A. Avaliação da Exposição a que estão Submetidos os Aplicadores de Agrotóxicos da Cultura da Uva, Estudo de Caso: o Vale do Sub-médio São Francisco. Monografia - Engenharia de Segurança do /trabalho. UFPB/ João Pessoa - PB, 2004.

[27] Gowreesh, S., Sreenivasalu Reddy, N. and Yogananda Murthy, NV. Convective Heat Transfer Analysis of a Aero Gas Turbine Blade Using Ansys, International Journal of Mechanics and Solids. 4, 2009, 39-46.

[28] B. Deepanraj, P. Lawrence, G. Sankaranarayanan, Theoretical analysis of gas turbine blade by Finite element method, Scientific World, Vol. 9, No. 9, July 2011, 29-33. 
[29] Gurrappa, I. V. S. Yashwanth, A. K. Gogia, The Behaviour of Superalloys in Marine Gas Turbine Engine Conditions, Journal of Surface Engineered Materials and Advanced Technology, 1, 2011, 144-149.

[30] Brooks CR. Heat treatment, structure and properties of nonferrous alloys. New York: ASM; 1984, 139-228.

[31] Huda Z. Development of heat-treatment process for a P/M superalloy for turbine blades. Mater 28(5), Des 2007; 1664-7.

[32] Boyce MP., The gas turbine handbook. 2nd ed. Houston, Texas: Gulf Professional Publishing; 2002, 411.

*Corresponding author.

E-mail address: francisco_alvesp@yahoo.com.br 